\title{
Social Networks and the Management of Water Resources for Agriculture in Rio Caia Catchment (Portugal)
}

\author{
Luís Rodrigues, Carlos Russo Machado*, Nelson Lourenço \\ Centro de Investigação da Universidade Atlântica, Antiga Fábrica da Pólvora de Barcarena \\ 2745-615 Barcarena, Portugal
}

\begin{abstract}
The involvement of local people in the management of scarce resources, such as water available for agriculture, is a desirable approach to address some of the difficulties in the decision-making processes. This paper reports the experience of a research team of sociologists and geographers involved in the MULINO project (Multi-sectoral, Integrated and Operational decision support system for sustainable use of water resources at the catchment scale). In the framework of this international and interdisciplinary project, a social network analysis was developed in a catchment of south Portugal. This analysis was structured in five fundamental steps: Stakeholder Identification; Data Collection; Data Treatment; Network Visualisation; and Local Network Analysis. The information was gathered mainly through a questionnaire, bibliographic references, statistical inputs and field observations. In order to obtain a typology of stakeholders and their interactions, a factorial analysis of multiple correspondences and a cluster analysis were applied. The social network analysis, which is the measuring and visualisation of relationships and flows between people, groups, organisations or other information/knowledge processing entities, supported the description of two types of patterns that link different sets of actors: social groups (sets of actors closely linked together) and social positions (sets of actors who are linked into the overall social system in similar ways). The analysis of the Caia Catchment network shows that this type of analysis is important not only as a means to characterising certain parameters about the network's characteristics, but also as a significant tool to help improve the communication within the social network.
\end{abstract}

Key-words: governance; irrigated agriculture; social networks; water management.

\section{Introduction}

Decades of human pressure on natural resources have resulted in a new approach to development, which also points to the future but, contrarily to prior approaches, "... to a bleak future of scarcities rather than a bright future of progress..." (Sachs, 1995). Development is only possible when economic fairness, social equity and environmental sustainability are guaranteed. Finding solutions to these problems is one of the main challenges of our society.

The involvement of state organisms and local communities in the development processes is a priority for almost all international support programmes. This priority is supported by the perspective that decisions should be taken as close as possible to the affected citizens (the subsidiary principle), as well as by the principles of local participation and decentralisation. This is so thanks to inefficient aspects of current development processes which, up to a few years ago, were very limited in economic terms and somehow rather distant from the local reality (Jorge et al., 2002).

Nowadays, the concept of sustainable development has inscribed in itself the linkages of economy and environment because the societies base their growth on the extraction, transformation and consumption of natural resources. Therefore, sustainable development demands an integrated and interactive approach that allows for an understanding of the complex relationship between society and nature with regard human rights, and assuming that the environment is a vital dimension of the future of human kind (Lourenço, 2001).

The way societies organise themselves and

* Corresponding Author: Tel.: +351 214398227; Fax: +351 214398246. E-mail address: cmachado@uatla.pt 
establish rules to govern their actions will play a major role in determining whether they move toward more sustainable paths. But good governance requires reforming decision-making processes to increase opportunities for public participation; this includes a wide variety of activities ranging from consultation hearings as part of an environmental impact assessment, to co-management of natural resources. Therefore it requires public debate and a problem-solving capacity (Risse, 2002).

The systems that society has developed to govern itself, which are generally based on the nation state, are becoming increasingly complex nowadays; it seems necessary to discuss the basic structures of governance, in order to manage the conflicting and changing economic, social and environmental requirements of modern governance systems. Moreover, individuals, households and communities are seeking greater control over their own destinies, while the boundaries between the public and private spheres are continually shifting (Lourenço et al., 2002). Therefore, governance arises as a key issue for the implementation of sustainable development. It is an approach through which we can understand and describe the systems, networks, practices and dynamics of governing. Good governance depends on the legitimacy of the political system and on the respect shown by the people for its institutions. It also depends on the capacity of such institutions to respond to problems, and to achieve social consensus through agreements and compromise (Lourenço et al., 2002).

According to Cernea (1985), participation has to do with giving people power to mobilise their own capacities, to be social actors instead of passive subjects, manage resources, make decisions and control the activities that affect their lives. This type of co-management requires power sharing between government agencies and citizens with a stake in the common pool of resources and territory. It emphasises a bottomup rather than top-down process of participation and implies user groups playing an active role in decision-making. The local communities of stakeholders should play a central role in identifying resources, defining development priorities, choosing and adapting technologies and implementing management practices.

The participation of local communities in- volves the different stakeholders present in the region, and therefore applies to an integrated, multi-level and multi-disciplinary approach. The participation in the management of territory and natural resources is justified by the benefits to local communities resulting from the proximity of the local stakeholders to the resources, which could ensure a more adequate use; the expected increase of resource flows to rural populations, which can contribute to alleviating poverty, diversifying benefits and achieving a more equitable income distribution; the flexibility of the process, which can ensure a better adaptation to the context of uncertainty and change (Brown, 1999). However, integrating local people in the decision-making processes is not always successful. They should participate in the decision-making process but they must also benefit directly from the decisions taken (Cater and Goodall, 1992).

Every social system is structured in (formal or informal) networks. These social networks are structured by the different social, economic and political actors that are involved in a given region and have a key role in the effective management of territories and resources. They constitute structures of opportunity and constraint for the stakeholders and they have proven to be crucial to (EC, 2003):

- facilitate information flows and produce better-informed and more creative decision making (reducing uncertainty) by developing a broader knowledge base through the use of stakeholders' knowledge and experience; - stimulate a more open and integrated governance, more transparency in the decision process and increase stakeholders acceptance, fewer delays and more effective implementation;

- promote social learning as a consequence of a constructive dialogue in which all interested parties involved in the networks (stakeholders, governments and experts) learn from each other.

Social networks should coordinate contacts between the various individual and collective actors in a given region and encourage them to work together in order to harmonise their objectives and concerns. The success of the local network, as a support instrument for managing territory and natural resources, partly depends on the type of participation of the various stake- 


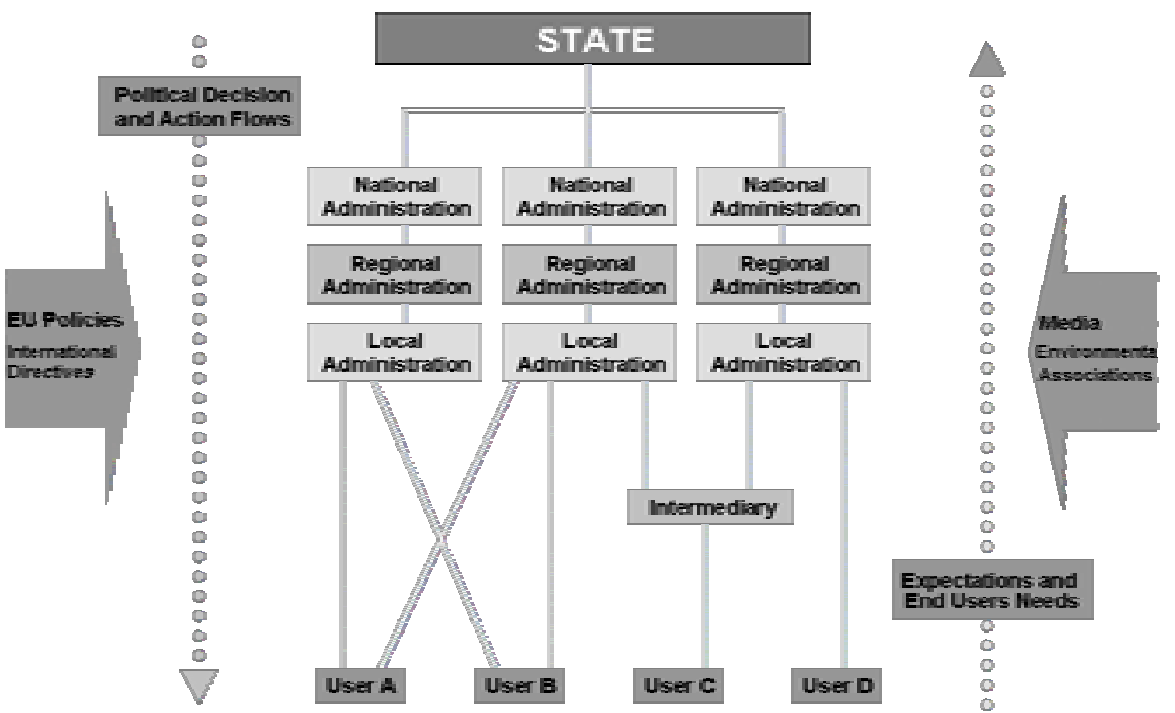

Figure 1. The structure of a social network present in a catchment (Source: Lourenço et al., 2001). holders located in the region. Involving the various actors from the beginning of the process is a way of ensuring the success of responses by the development and implementation of decision-making support tools. Therefore, the final decision is more likely to integrate the expectations of the various actors that have active interests in the territory.

The relationships among the various social actors (whether individual or collective), in any area, are structured in the form of networks. In reality, "...the people belong not only to groups but to networks as well, the groups being the reflection of the structural relationships that tie the individuals together..." (Degenne and Forsé, 1994). According to Wasserman and Faust (1994), a social network consists of a finite set of actors and the relation or relations defined in them. The actors are social entities, discrete individuals, corporate or collective social units. A basic assumption of the relationships formed to provide a network is that the social actors in a network are mutually dependent upon resources controlled by each other, and that there are benefits to be gained by pooling their resources. In a relatively static way, networks can be defined as "...systems of social actors that propagate among themselves information and resources across structures with strong connectivity with the objective of making common a variety of their internal environment. Aside from this, it is observed that the interactions with the external environment of the network arise from structures with a lesser degree of connectivity..." (Lemieux, 1999).

In the decision-making process, social networks work as an essential tool in the transmission and acceptance of normative systems, which will regulate the decision and allow for the identification of existing problems and potentialities, the assessment of proposals for sound intervention, and also the understanding of interactions and conflicts among the various social actors (Lourenço et al., 2001). Furthermore, social networks have a special role in the acceptance and diffusion of technological and organisational innovation. Thus, at local level it becomes imperative to consider the relationships among the various social actors as real interactions and therefore as local potentials and liabilities, thus guaranteeing the success of the decision-making process.

The networks that are established at a local level are integrated into larger networks (regional, national, and even international). The diagram in Figure 1 shows how the networks that are established within the context of the decision-making process are relatively centralised (Lourenço et al., 2001).

Thus, it can be observed that the transfer of resources and information fundamentally follows a somewhat hierarchical chain which encourages top-down communication and makes the reverse more difficult. It is therefore noted that horizontal communication among the various levels of the diagram is of lesser importance, 
although not non-existent. This indicates that we are not faced with an ideal network in which all the actors are at the same time transmitters and receivers of equal importance.

The diagram implies that in the internal environment of the network there are preferential transmission (and imposition) flows of the normative framework, as the actors do not all have an equal position. Nevertheless, this does not mean the acceptance of all the decisions, information, or actions transmitted from the higher levels. There can be diversity in perceptions about the potentials and problems of a given region due to the individual actor's proximity to local realities. These different perspectives may be configured in different views about development.

Social networks are frequently conflicting. The awareness of these conflicts is essential in order to understand the rationale of the networks and to understand where the obstacles to decision-making and implementation of the various policy measures lie. Sometimes conflict or obstacle arise, not as a result of varying perspectives of development, but from a lack of awareness of policy measures, or a lack of adequate training for their correct understanding and effective implementation. In this sense, it is very important to identify and characterise the various social actors (individual and collective) to understand their functions and levels of intervention, and to comprehend the types of relationships that are found among these actors that comprise the network.

On the other hand, another significant type of conflict is observed within the context of managing a finite natural resource, such as water. These conflicts arise from the different uses (within or outside the catchment) of this natural resource. It is therefore important to identify the various water uses of the catchments to be analysed. In the end, this contributes to the identification of the stakeholders, or in other words, the social actors that are found at the base of the local network.

As for the driving forces, it is necessary to proceed with their identification, both in terms of the internal environment of the network (for example: the main water uses, and the territorial dynamics that exert pressure on this resource), and in terms of those external driving forces that determine how the network works, i.e., national and supranational normative frameworks. These laws may be understood as external factors that influence the behaviour of the network by defining intervention norms and policy measures. They are restrictions that are imposed in general from the highest levels of the social network and to which the lowest levels must adapt.

However, they are not the only external factors that determine how these local networks operate. In fact, depending on the needs, expectations and conflicts of the local actors (water users) sometimes protest movements are generated that have an influence on the network of social relations, encouraging certain decisions and opposing others. The influence of these types of external factors is the opposite tothat of the normative framework: bottom-up, instead of top-down. Thus, transmission of information and intervention can be observed from the lowest levels of the network moving towards the higher ones. Here it becomes necessary to analyse the types of external factors that can constrain action, creating difficulties or guiding the process of decision-making along another path. Moreover, it is important to understand water users' capacity to organise themselves in action groups as well as the efficiency of their organisations.

\section{Materials and Methods}

The analysis of the social network of Rio Caia Catchment followed a methodological approach structured in five fundamental steps: Stakeholder Identification; Data Collection; Data Treatment; Network Visualisation; and Local Networks Analysis (Figure 2). The main goals of the analysis were: (i) to visualise communication flows and other stakeholders' interactions by using statistical data and diagrams; (ii) to examine the factors influencing the interactions; (iii) to analyse the association of interactions; (iv) to illustrate the implications of the relational data and situations where information flows do not create a formal group structure and (v) to make recommendations in order to increase the efficiency of decision-making processes by improving the share of resources. Social network studies have hardly ever collected information about all the relationships 
that actors have with all the other members of the social network (Kochen, 1989). Such an effort would be prohibitively expensive. These studies focus on the stakeholders' more relevant relationships with a set of their network members, e.g., those network members who provide a support to understand the decisional context in analysis.

The identification of decision makers and stakeholders to be interviewed was a dynamic process and evolved according to the development of the research and of the observers. In a first step this identification relied on work with privileged informers (Water Institute - INAG and Rural Development and Hydraulics Institute - IDRHA) to select the social actors (farmers, industrial entrepreneurs, environmentalists, technicians and or managers of public agencies, water suppliers, etc.) based on some pre-defined criteria. These criteria aimed at identifying individuals, groups or institutions that are water managers or actual and potential water users for different purposes. These actors would be: those that examine alternative strategies in water management; those ultimately affected, either positively (beneficiaries) or negatively, by the decisions; those intermediaries in the process of decision making and implementation; and those who can significantly influence, or are important to the success/failure, of the decision taken.

In this process a list was given of people and entities in the catchment to the stakeholders interviewed who were asked to identify a connection of some content. This procedure permitted the initial list of stakeholders structuring the social network to be increased. This process was repeated in the next interviews, and although this did not lead to an exhaustive list of all persons and stakeholders involved in the water management in the catchment, it provided the main actors. Furthermore, this approach is useful to start identifying the relative positioning of stakeholders in a network as well as the partitioning of subgroups (Haythornthwaite, 1996).

Collecting data based on the recall of the interviews, although widely used, is considered by some authors as less reliable than data gathered by direct observation (Bernard et al., 1981). Those answers are used to rank the relative frequency of contacts with other social actors, and the resulting rank can be biased because not all stakeholders are equally inscribed in the minds

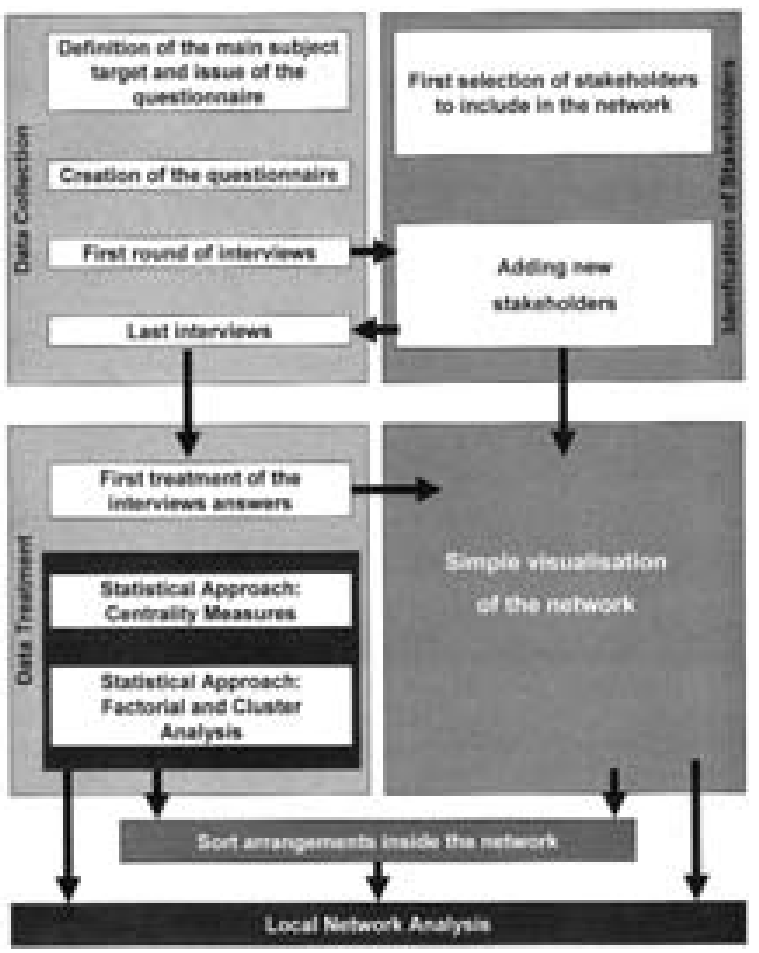

Figure 2. Methodological steps to analyse Caia's Local Network.

of the interviewees (Christensen et al., 1983). Therefore, the combination of data collection methods (questionnaires, interviews and observation) is considered the best approach by social network researchers.

Nevertheless, questionnaires are important to define groups of stakeholders and patterns of interactions. In addition to survey questionnaires, the research process made use of qualitative data gathered through analysis of the interviews and observations. Software applications such as SPSS were useful to organise this data and to investigate patterns among institutions, activities and behaviours. This process provided a means of integrating the analysis of social networks with a cognitive dimension.

The analysis of Caia's social network is based on the study of a set of 18 institutional actors that have some kind of influence on the decision-making process concerning the water management at local level. The information was gathered mainly through a questionnaire, bibliographic references, statistical inputs and field observations. The questionnaire was developed in ten main topics, which could be summarised 
in the following subjects: Identification of the stakeholders' objectives and responsibilities for the use and management of water resources; Review of the stakeholders' means of intervention to accomplish their objectives Water availability; Identification of the state of water resources and the main management problems; Identification of response actions and means of intervention for the resolution of the problems; Conflicts related with water uses; Description of the institutional framework; Water price; Support to optimise water resource management; Information; Local network intensity.

\section{Network analysis}

The analysis of local network data generally follows a sequence of steps that aim at identifying typologies of actors and interactions. The first step involves two different types of analysis. One refers to the entire network analysis and the other to the centrality analysis (Wellman, 1992).

The entire network analysis examines the structure of social networks (including groups or clusters), as well as the networks' composition, functioning, and links to external situations. With this analysis it is possible to examine questions such as: Who interacts with whom, about what and how? How are ties and relationships maintained, or changed, over time? How do interpersonal relations such as professional meetings, work role and organisational position affect the whole social network?

The approach to the entire network analysis focused on the description of the structure of the local network through the examination of the size, density, and cohesion of the network.

Density is a measure to describe how many entities are related to others in a given network. It refers to the total number of connections existent in the network divided by the total number of possible connexions between all the actors. The maximum value of density in a network is 1 .

Cohesion is also a measure to describe the interconnectedness of actors in a network. However, it refers only to the mutual connections existent in the network divided by the total number of possible mutual connections between all the actors. Therefore, this measure excludes all the non bidirectional connections.

The centrality analysis is the most important way of identifying the actors that play the most relevant roles within the network and refers to the extent to which a network revolves around a single node (Everett and Borgatti, 1999).

Centrality is an attribute of the nodes in a network that refers to the structural position of an actor within the network. Measuring the centrality of the different nodes is a way of assessing the importance and influence of an actor within the network. According to Freeman (1979), from the individual measure of centrality, it is possible to estimate a global degree of centralisation of the network and the three most widely used measures of centrality can answer some questions:

- degree centrality measures the number of direct links of each actor with the other actors within the network and it is often normalised as a percentage of the degrees in a network. This coefficient describes the actor or actors with the largest number of direct links and, therefore with widest access to the network. It allows the following questions to be answered: How active is each social actor within the network? Who is the most active social actor within the network?

- in a non-symmetric network it is important to distinguish centrality based on in-degree from centrality based on out-degree. The relative out-degree of a node is the total number of linkages incident from it divided by the number of all other nodes. The relative in-degree of a node is the total number of linkages incident to it divided by the number of all other nodes;

- closeness centrality measures the average distance of a node to all other nodes in the network. Since this coefficient characterises how close each actor is to all the other actors of the network it allows the following question to be answered: Who is the social actor with fastest access to all the nodes within the network?

- betweenness centrality measures the extent to which each social actor has to go through a given actor to become connected to the others. Therefore, the more people depend on a given actor to make connections with other people, the more central that actor is. It is measured through the number of shortest paths between different actors that pass through a given node. This coefficient de- 
scribes the actor or actors with highest levels of betweenness and that have a strong influence over what flows in the network. It allows the following question to be answered: Who is the best-connected social actor within the network?

One of the outputs of this analysis was the identification of stakeholders that reflect the highest number of contacts. The relationship between the centralities of all nodes can reveal much about the overall network structure. A much-centralised network is dominated by one or a few very central nodes. If these nodes are removed or damaged, the network quickly fragments into unconnected sub-networks. Highly central nodes can become critical points of failure. A network with a low centralisation score is not dominated by one or a few nodes. Such a network has no individual points of failure. It is resilient in the face of many intentional attacks or random failures. Some nodes or links can fail while allowing the remaining nodes to still reach each other over other paths (Freeman, 1979). The typology of stakeholders was characterised by content, type, direction and intensity of the interactions. The content of an interaction refers to the resource that is exchanged. The relationships between two actors can be directed or undirected. For example, one stakeholder may give technical support to second stakeholders to solve one problem regarding the water supply. There are two relations here: giving support and receiving support. Alternately, stakeholders may share a mutual relationship, i.e., they both maintain the relationship and there is no specific direction to it. However, while they both share the outcomes of the connector, the relationship may be unbalanced: one actor may claim a close relationship and the other a weaker relationship, or communication may be initiated more frequently by one actor than the other. Thus, while the relationship is shared, its expression may be asymmetrical.

Case study overview: Physical and socio-economic frame of Caia catchment

Caia River catchment is located in a region of South Portugal, the Alentejo, near the border with Spain (Figure 3). The Alentejo is one of the most easily identifiable regions in Portugal as economically and socially peripheral. Environmentally, it is likewise a region where extreme climatic conditions and insufficiently fertile land limit the development of competitive agriculture. Nevertheless, there are exceptions. Wine and olive oil, which are well adapted to

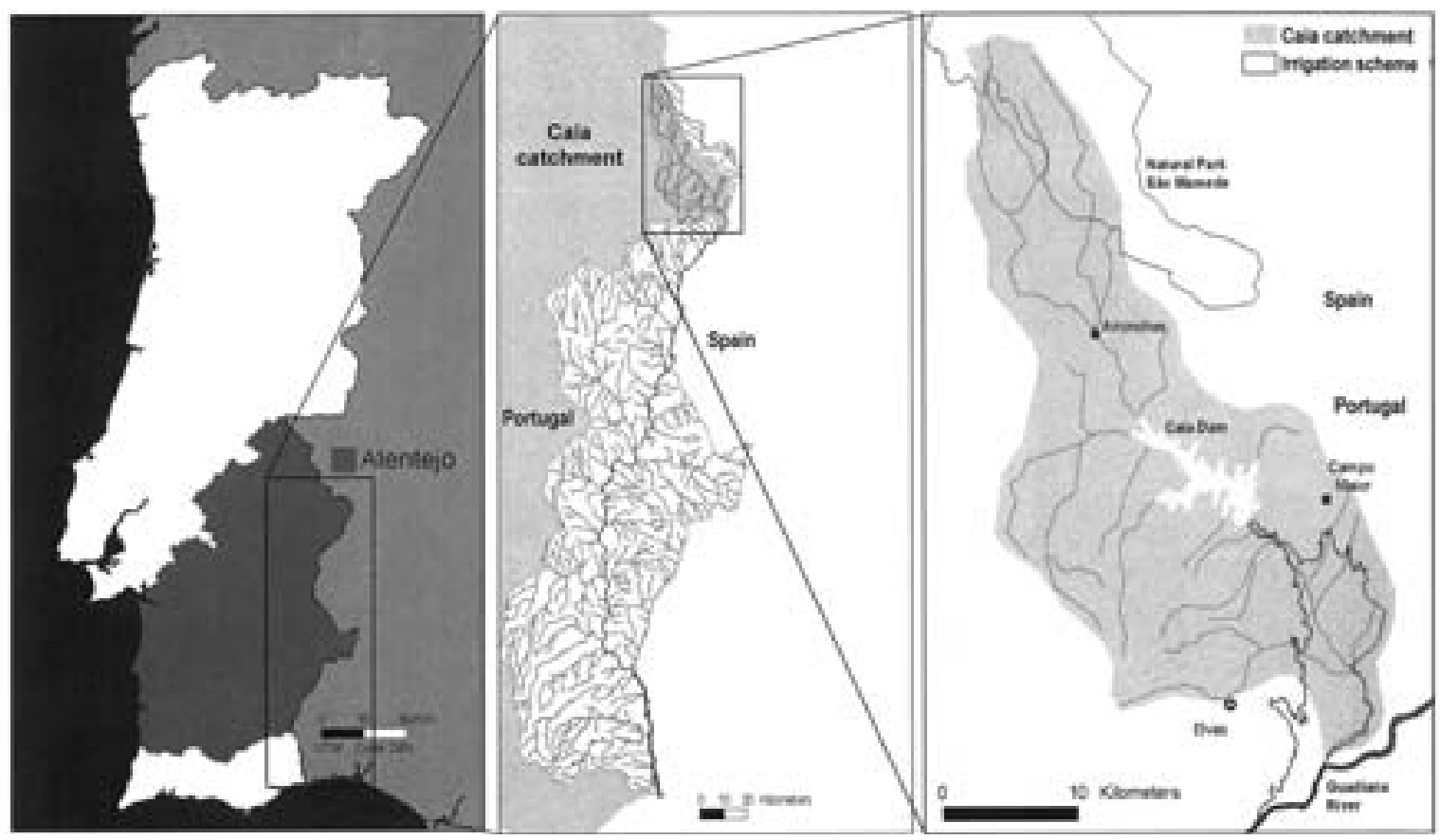

Figure 3. Rio Caia Catchment and irrigation perimeter situation in Guadiana catchment. 
these biophysical conditions, are very competitive with significant market niches, especially if they are origin labelled products.

Alentejo is also an entirely different place in terms of its agrarian structure: it owes its ecological, economic and social peculiarity to the dominant large landowner system of extensive monoculture. As such, it can be considered the periphery of the periphery inasmuch as it is an under-populated, non-industrialised and deeply marginalised region.

The Alentejo region with a low population density (large number of municipalities have less than 20 inhabitants $/ \mathrm{km}^{2}$ ) is dominated by large and very large holdings and the land of each farm unit is relatively concentrated into a few blocks. Agricultural and forestry activities remain responsible for the employment of a significant percentage of the active population. In recent years, there has been a sharp increase in the active population employed in services, particularly in the public and private services. This fact demonstrates the non-existence of economic activities that function as a viable alternative to agriculture. Thus, population settlement is difficult, so much so that migratory movements continue both to other regions of the country and abroad.

The landscape of Alentejo, which is dominated by the huge peneplain of the Alentejo with small ranges of hills, is marked by the presence of Montado oak plantation which forms an extensive land-use system of the agro-silvo-pastoral kind. It results from the selection of species from the Mediterranean forest, which man developed over the last two centuries (Natividade, 1950). It is particularly well adapted to the climate and soil constraints and is made possible by the large size of the holdings in the Alentejo. In terms of land use, the montado is used for growing cereals in rotation with planted pastures which are generally followed for four or five years by a fallow period during which the shrub covering increases. Apart from protecting the soil, this shrub layer allows for nutrients to be fixed in the soil and for the natural re-growth of the cork oaks. At the end of this fallow period, the land is ploughed and the scrub cut back. However, various factors have contributed to the degradation of this land-use system.

In the $20^{\text {th }}$ century, the Wheat Campaigns in the thirties and the mechanisation of cereal growing since the sixties, initiated intensive phases of cereal growing and pasture use that exert a great deal of pressure on the montado in the Alentejo. African swine fever, which spread in Portugal at the beginning of the seventies, led to the end of extensive Iberian pig farming. For these reasons the economic viability of the holm oak montado almost disappeared and continues in decline and the density of its trees is diminishing; the latter were generally transformed into vegetable coal, giving way to clean land where the mechanisation of cereal farming was possible (Ferreira et al., 1993).

In recent years, the area of cork oak montado has stabilised; however, intensive cereal growing and pasture use do not allow for the natural regeneration of the cork oaks and as a result the trees are generally old, in decline and produce less cork (Daveau, 1995). The periods of drought felt in the nineties have also contributed to the general weakening of these trees.

Most of the eleven irrigation schemes in the Alentejo are limited in size and are unable to resist a few successive years of drought. Moreover, they are characterised by very low levels of land and water use and until very recently they were concentrated largely in monocultures of rice and tomato for industry. The Irrigation Plan of the Alentejo, drawn up in the 50s-60s, provides for the construction of a large dam (Alqueva) that should theoretically irrigate 180000 ha. At present, rice production has almost disappeared and tomato production is limited. The Alqueva irrigation scheme, presently under construction, will provide for the irrigation of around 110000 ha, but its effects will only be seen in the medium/long-term.

Caia River catchment is a tributary of one of the main Iberian rivers, the Guadiana River; its river basin is around $780 \mathrm{~km}^{2}$ and it has an average altitude of $334 \mathrm{~m}$. The slope in almost all of the catchment varies from $0-5 \%$; however, in the upper land (Serra de São Mamede, $937 \mathrm{~m}$ ) it can reach $25-35 \%$. The Mediterranean climate dominates in the region although the distance from the sea accentuates some climatic features with temperatures becoming more extreme. The topography also has an effect on the spatial distribution of the rainfall. The upper areas of the catchment in the northern boundaries, with an elevation around 700-930 m, register $800-1000 \mathrm{~mm}$ of rain a year (SNIRH, 2001). The rain is relatively scarce and almost 


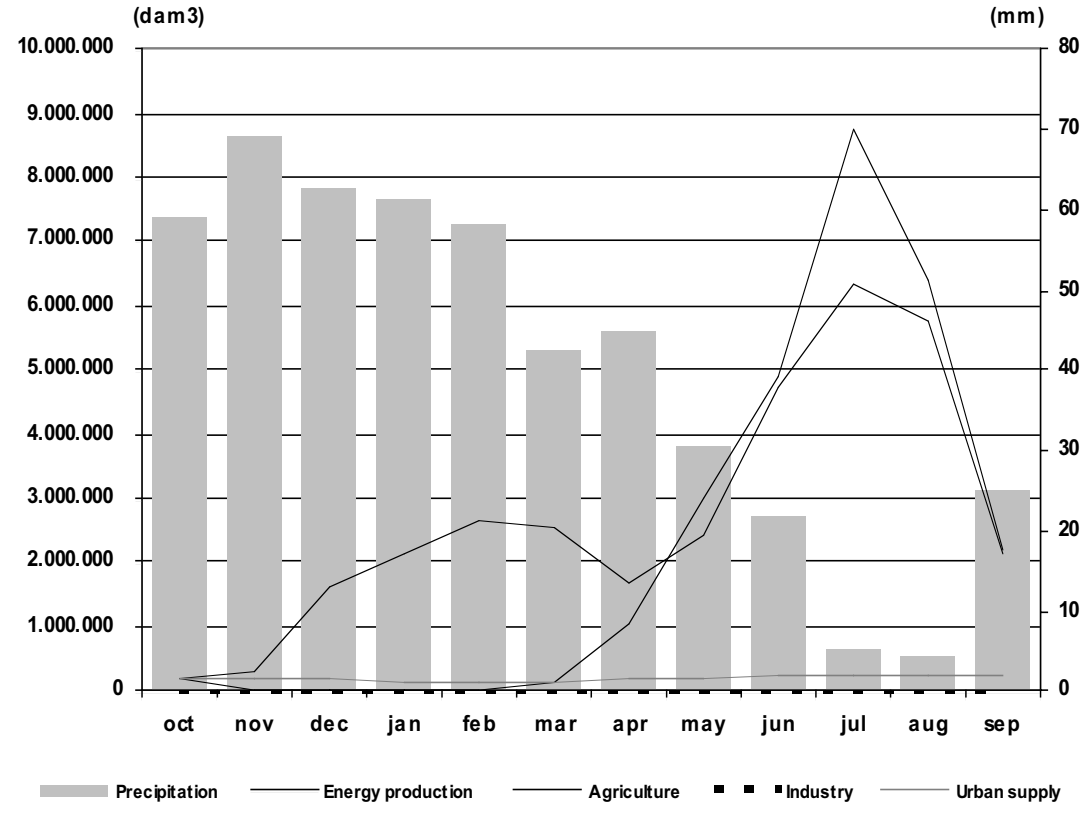

Figure 4. Average annual water consumption and average crop consumption 1990-2000 (Faria and Paz, 2002).
$80 \%$ of annual precipitation occurs between October and April. The annual average precipitation is about $500-600 \mathrm{~mm}$, attaining $1000 \mathrm{~mm}$ in the high lands of Caia catchment. The occurrence of heavy downpours in the spring and autumn and the great irregularities in the yearly rainfall make it difficult to plan crops and the necessary irrigation.

The rocky layer is fundamentally marked by the presence of schists, greywackes and granites, and occasionally, marble. With the exception of small and narrow alluvial plains, the soils in this region are generally stony, not very developed, with a scarcity of organic matter, a low capacity for water retention, often highly eroded and largely unsuitable for agriculture.

The average size of the farms in all the catchment is around 52 ha. However, the average size of the farm drops to 14 ha when only the area of the irrigation scheme is considered. Outside the irrigation scheme, the land is dominated by medium-size and large-size farms, and is used extensively with crops rotating with pasture and being left fallow over long periods, very often under a cover of scattered cork and/or Holm oaks. Almost all the agricultural land is owned by the farmers and there is little leasing. There are few young farmers; on the contrary, farmers over the age of 65 years continue to play a very important role in the management of the region's farms. However, these farmers only ded- icate a part of their time to the farm. There is only a significant percentage of full-time farmers in the area of the irrigation perimeter.

Between 1963-1967 a reservoir was created by the Caia dam. Over the last 30 years, this reservoir has triggered the conversion of the agricultural production systems from rainfed farming to intensive irrigated productions in a perimeter of about 7200 ha. This reservoir, with a total capacity of $203 \mathrm{hm}^{3}$, is the source of water extraction for different uses and it supplies about 500 farms for agricultural work (Faria and Paz, 2002).

In the Caia Catchment multi-purpose water management is a significant subject. Although the main water use is associated with agriculture (91.2\% in 1996), which is the main land use in terms of surface in the region, there are two other significant water uses in the catchment: industrial $(8.7 \%)$ and public supply $(0.1 \%)$ for two municipalities (Faria and Paz, 2002). Furthermore, water uses such as those related with recreational activities and ecological interests are relevant from the socio-economic viewpoint. Agriculture is thus competing with other sectors for the use of water, and, as a result the management of water quantity and the preservation of water quality have become very important issues in the Caia Catchment. Given the dominant weight of the agricultural use of water, the conflicts between uses and users are significant mainly during periods of water scarcity: dry years and dry seasons. 
The main irrigated crops in this area are rice, maize and tomato. In recent years, due mainly to the insufficient water stored in the reservoir, sunflowers have taken on more importance as the rice area was reduced. There has also been an increase in the complementary irrigation of wheat (Faria and Paz, 2002).

The great irregularity of seasonal rain distribution in the region, with periods of severe drought followed sometimes by periods of extreme abundance of water, makes crop planning difficult, and sometimes causes conflicts among the different waters users in the catchment. Irrigation in this region is not seen as a means of increasing agricultural productivity. In fact, it is seen as an essential production factor to ensure the economic viability of the farms. Therefore, there is a strong seasonality (Figure 4) in the use of water from the reservoir, which is almost depleted at the end of the irrigation period (corresponding to the end of dry season), especially in the driest years.

\section{Results and Discussion}

The main goal of the analysis was to examine the interactions among stakeholders within the network. The two objectives of the analysis were: (I) to determine if there are any groups of individual agents whose patterns of interactions are sufficiently similar to be considered as a type of stakeholders; (II) to describe the patterns of interactions among stakeholders (typifying the water management process), and to identify their roles in the network.

Caia's social network has 18 nodes (stakeholders) with a web of 112 ties (interactions) connecting them. It is also a non-symmetric network, which means that not all the stakeholders maintain reciprocated linkages. This social network has a density of 0.37 , i.e. only $37 \%$ of all possible direct linkages are present. Furthermore, the cohesion is also low (0.20), showing that only $20 \%$ of the connections are reciprocated. This data tells us that there is potential to increase the interactions among stakeholders in this small network, which could contribute to improving the processes of water management in the catchment.

From the centrality analysis it is possible to say that there are no isolated actors within the Caia river catchment network. Somehow each actor is able to reach all the others in the network, directly or indirectly. However, the links between the different stakeholders are not always reciprocated. In fact, it is possible to observe some actors that interact with others with a leading role. To determine which of the actors are more important, the analysis considered all the direct ties made by an actor (both originated and received) and the indirect ties (paths). The usual parameters of centrality were used to examine the centrality of the stakeholders within this network: degree centrality, out-degree centrality, in-degree centrality, closeness centrality and betweenness centrality (Table 1). Furthermore, three classes of prominence were considered: local centrality, related with the outdegree; local prestige, related with the in-degree; and global centrality, measured by indexes such as "degree" "closeness" and "betweenness".

The analysis of Table 1 reveals that the $\mathrm{Ca}$ ia Irrigation Board is the stakeholder with the highest degree of centrality (0.79), i.e. it is the actor with more connections and hence can directly affect more other actors. It is the social actor with most influence (highest out-degree), most prominence (highest in-degree), is closest to the others (highest closeness) and the actor with the most favoured position (highest betweenness) because many other actors depend on it to make connections with other actors. This central position makes this stakeholder more visible to the community of water users and results from its role in supplying water for irrigation. In effect, the existence of one actor with greater local centrality is very significant in order to understand the internal environment of the local network. Therefore, Caia Irrigation Board is the most involved stakeholder in water management, and it can be considered as the most important channel for the diffusion of information and innovations (decisions, technical support, procedures, etc.) serving also as a liaison between different actors in the network.

Within Caia network, other stakeholders that play central roles can also be found, i.e. IDRHA, the national authority responsible for Rural Development and Hydraulics, which has significant values in all the parameters. The high value of Betweenness of IDRHA represents its great potential to control interface relationships. IDRHA, as a national authority, represents the 
Table 1. Measures of centrality according Caia stakeholders in the networks.

\begin{tabular}{lccccc}
\hline Social Network in Caia Catchment & \multicolumn{4}{c}{ Centrality coefficients } \\
& Degree & Out-Degree & In-Degree & Closeness & Betweenness \\
\hline 0 Caia Irrigation Board & 0,794 & 0,765 & 0,824 & 0,048 & 102,152 \\
1 North Alentejo Municipalities Association & 0,412 & 0,353 & 0,471 & 0,029 & 9,483 \\
2 Portalegre Municipality & 0,441 & 0,529 & 0,353 & 0,032 & 9,205 \\
3 Arronches Municipality & 0,265 & 0,235 & 0,294 & 0,027 & 1,786 \\
4 Elvas Municipality & 0,441 & 0,294 & 0,588 & 0,033 & 10,024 \\
5 Campo Maior Municipality & 0,265 & 0,176 & 0,353 & 0,030 & 3,481 \\
6 Olive Oil Producers Association & 0,294 & 0,412 & 0,176 & 0,036 & 3,417 \\
7 ALTOL (Tomato Producers Group) & 0,353 & 0,529 & 0,176 & 0,040 & 9,333 \\
8 CERSUL (Cereals Producers Association) & 0,206 & 0,294 & 0,118 & 0,034 & 1,000 \\
9 Beetroot Producers & 0,147 & 0,059 & 0,235 & 0,027 & 0,000 \\
10 Agroraiana (Farmers Association) & 0,324 & 0,412 & 0,235 & 0,037 & 9,843 \\
11 Reg. Direct. for Agriculture & 0,353 & 0,176 & 0,529 & 0,031 & 5,638 \\
12 Reg. Direct. for Environ. and Spatial Planning & 0,353 & 0,353 & 0,353 & 0,034 & 4,379 \\
13 ESA (Agrarian School) & 0,265 & 0,353 & 0,176 & 0,034 & 1,286 \\
14 GEDA (Ecologist and Adventure Sports Group) & 0,265 & 0,412 & 0,118 & 0,037 & 5,050 \\
15 Water Supply Company & 0,412 & 0,471 & 0,353 & 0,037 & 11,814 \\
16 INAG (Water Institute) & 0,441 & 0,353 & 0,529 & 0,034 & 13,664 \\
17 IDHRA (Rural Development and Hydraulics & 0,559 & 0,412 & 0,706 & 0,036 & 25,445 \\
Institute) & & & & & \\
\hline
\end{tabular}

most central position between the local stakeholders and other entities situated outside the catchment.

GEDA and INAG, the national authority for water management, are quite close to the other actors inside this network., These two stakeholders have completely different characteristics but are important to maintain regular patterns of relationships between different levels of water management interacting within Caia network. The Water Institute supervises all the activities related with the Caia dam reservoir and all entities that are operating in this area depend directly on its decisions. This explains the important role played by this institution. GEDA is the only NGO operating with its head office located inside the limits of Caia river basin. This actor acquired its position within Caia network acting almost as originator of the contacts. Its prominence can be important to obtain support to launch initiatives or just to influence the decision-making process.

Despite the lack of isolated actors, some of the stakeholders are not so extensively involved in relationships with all the actors but have a peripheral position within the social network. Beetroot producers can be considered the most isolated stakeholder within Caia's network. The centrality coefficients of this actor show the low communication activity with the other network nodes.
Arronches municipality is another example of exclusion in Caia network, although this stakeholder is reasonable well connected with the other municipalities. Another peripheral stakeholder is the NGO GEDA. In this case, it is possible to observe an attempt to become more integrated in the network. In fact, although the low in-degree, this stakeholder has a relatively high out-degree, showing that is in some way attempting to compensate the lack of contacts received by contacting with lots of other actors in the network.

Centrality within the groups and keystone entities Another perspective of centrality is to examine it from the viewpoint of each group identified with the cluster analysis. With this procedure, sub-structures can be found and other centralities seen and this contributes to the definition of other keystone entities. The main reason for defining and detecting groups in the Caia network is to obtain data zooming/description of patterns of the observed structures.

In a preliminary analysis of the groups, Caia's network shows a sample of a highly interconnected set of entities sharing similar interests. Nevertheless, global values of closeness and betweenness reveal important differences that make other keystone actors emerge. Inside the group of farmers' associations (Cluster 1) it is 
Table 2. Measures of centrality by groups of stakeholders.

\begin{tabular}{|c|c|c|c|c|c|c|}
\hline \multicolumn{2}{|c|}{ Cluster Node } & \multirow{2}{*}{$\frac{\text { Out-Degree }}{10}$} & \multirow{2}{*}{$\frac{\text { In-Degree }}{23}$} & \multirow{2}{*}{$\frac{\text { Degree }}{4.7}$} & \multirow{2}{*}{$\frac{\text { Closeness }}{0.14}$} & \multirow{2}{*}{$\frac{\text { Betweenness }}{18.7}$} \\
\hline 1 & Caia Irrigation Board & & & & & \\
\hline & Olive Oil Producers Association & 3 & 7 & 1.4 & 0.10 & 0.3 \\
\hline & ALTOL (Tomato Producers Group) & 17 & 5 & 3.1 & 0.14 & 3.2 \\
\hline & CERSUL (Cereals Producers Association) & 7 & 6 & 1.9 & 0.13 & 1.0 \\
\hline & Beetroot Producers & 4 & 8 & 1.7 & 0.08 & 0.0 \\
\hline & Agroraiana (Farmers Association) & 6 & 5 & 1.6 & 0.11 & 3.8 \\
\hline & ESA (Agrarian School) & 4 & 2 & 0.9 & 0.08 & 0.0 \\
\hline & GEDA (Ecologist and Adventure Sports Group) & 5 & 0 & 0.7 & 0.09 & 0.0 \\
\hline \multirow[t]{5}{*}{2} & North Alentejo Municipalities Association & 2 & 6 & 2.0 & 0.17 & 0.0 \\
\hline & Reg. Direct. for Environ. and Spatial Planning & 6 & 8 & 3.5 & 0.25 & 3.5 \\
\hline & Water Supply Company & 1 & 3 & 1.0 & 0.14 & 0.0 \\
\hline & INAG (Water Institute) & 10 & 8 & 4.5 & 0.25 & 2.0 \\
\hline & $\begin{array}{l}\text { IDHRA (Rural Development and } \\
\text { Hydraulics Institute) }\end{array}$ & 12 & 6 & 4.5 & 0.20 & 0.5 \\
\hline \multirow[t]{5}{*}{3} & Portalegre Municipality & 8 & 4 & 3.0 & 0.25 & 2.5 \\
\hline & Arronches Municipality & 9 & 3 & 3.0 & 0.25 & 1.0 \\
\hline & Elvas Municipality & 2 & 5 & 1.8 & 0.17 & 0.0 \\
\hline & Campo Maior Municipality & 3 & 5 & 2.0 & 0.17 & 0.5 \\
\hline & Reg. Direct. for Agriculture & 0 & 5 & 1.3 & 0.00 & 0.0 \\
\hline
\end{tabular}

interesting to see that the Cereal Producers Association starts the most contacts (Node 7). Nevertheless, Caia Irrigation Board is still the most central and prominent stakeholder inside this group.

Looking inside Cluster 2, it is possible to see that IDHRA lost importance, when compared with its prominence in the global analysis of the network. On the other hand, INAG increase their comparative significance, and are the most prominent entity in this cluster. This means that if the objective is to access the part of the network most related with national and regional level of decision-making, this can be most successfully achieved with INAG. However, if the objective is to go into an entity with more significance in transversal contacts with local entities, IDHRA is clearly the best alternative in this group.

In Cluster 3 (mainly related with municipalities), the Portalegre municipality is the most central and prominent stakeholder. With regard the prestige of Portalegre municipality it is important to refer that the president of this entity is also responsible for other associations that were not considered in this study (Portalegre Wine Association; and Portalegre Farmers Association). The individual prestige of its president is certainly one of the main reasons for Portalegre municipality level of centrality with- in Caia's network. The Regional Directorate for Agriculture that does not start any contact with other node of the group is included inside this cluster as a residual node.

\section{Typologies of Stakeholders}

Another step in the analysis of the social network in Caia Catchment was the identification of sub-groups within the network. In addition to considering the interactions between the different actors, this analysis also examined four other dimensions of interactions: frequency, objectives, how the interactions were produced and the geographic location of the different actors. With these attributes for each actor, a hierarchical cluster analysis was applied, allowing the identification of three structural clusters (Figure 5). Cluster 1 is essentially made up of farmers' associations; Cluster 2 largely encompasses the national and regional administrative authorities; and Cluster 3 comprises basically the municipalities of the catchment.

The hierarchical cluster analysis reinforced the idea that one group of stakeholders (Cluster 1 of farmer associations) is stronger than the others. This group of stakeholders can be characterised by the high frequency of relationships established among them. The Cluster 2 is not so strong due to its division into two sub-groups: the national authorities and the regional authorities. 


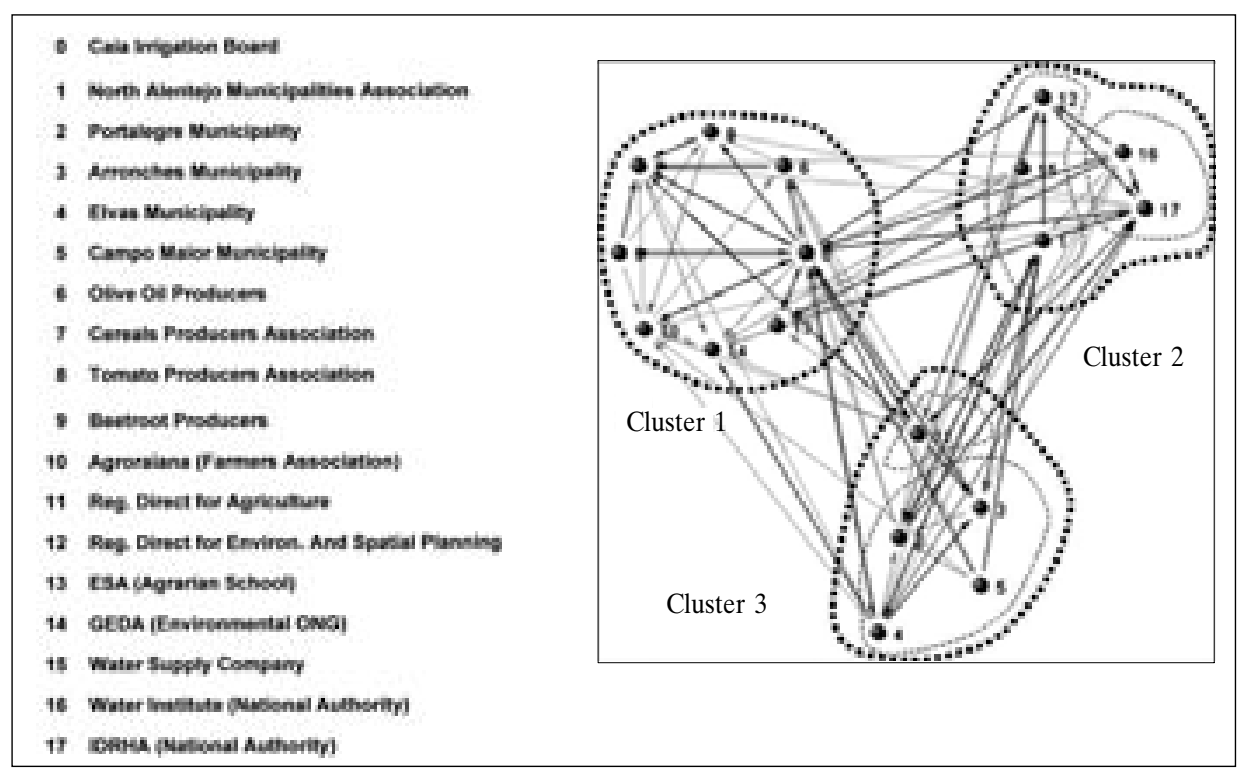

Figure 5. Base image of stakeholders' positional analysis among the Caia network.
In Cluster 3, one stakeholder (Regional Directory of Agriculture) is isolated when a more detailed analysis is performed. This means that there is a certain uncertainty about the position of this stakeholder in this group. On one hand, this regional authority has similar relationship characteristics with the municipalities; on the other hand, this is a regional authority with other expertise which is quite different from the municipalities.

A more detailed reading of the interactions established within the social network present in Caia catchment allows us to observe how the different actors can be organised. This thematic analysis enables us to associate the different stakeholders in accordance with different perspectives about concrete issues which that can have significant effects on the decision-making process. Although not developed in this paper, it seems important to give the example of some different associations of groups of actors resulting from their perceptions in relation to essen-

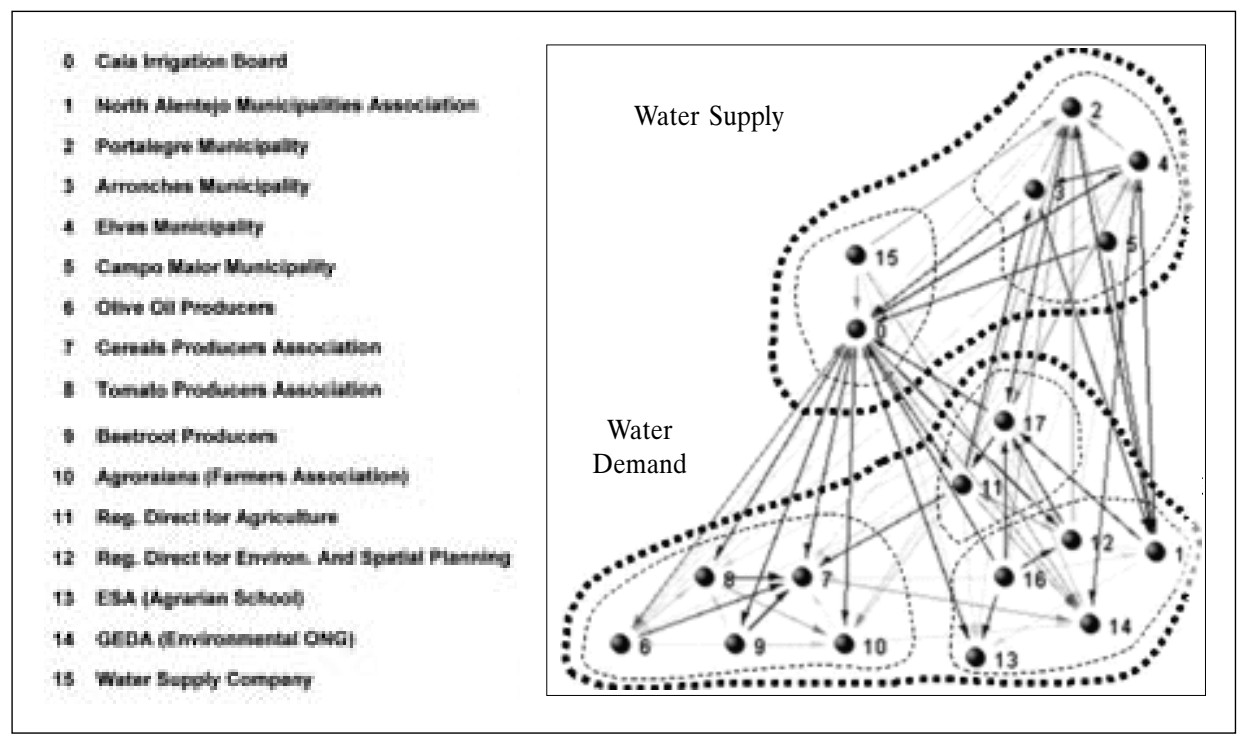

Figure 6. Stakeholders position among the Caia network according to their specific objectives. 
Figure 7. Perspectives of stakeholders about their perceptions on water availability.

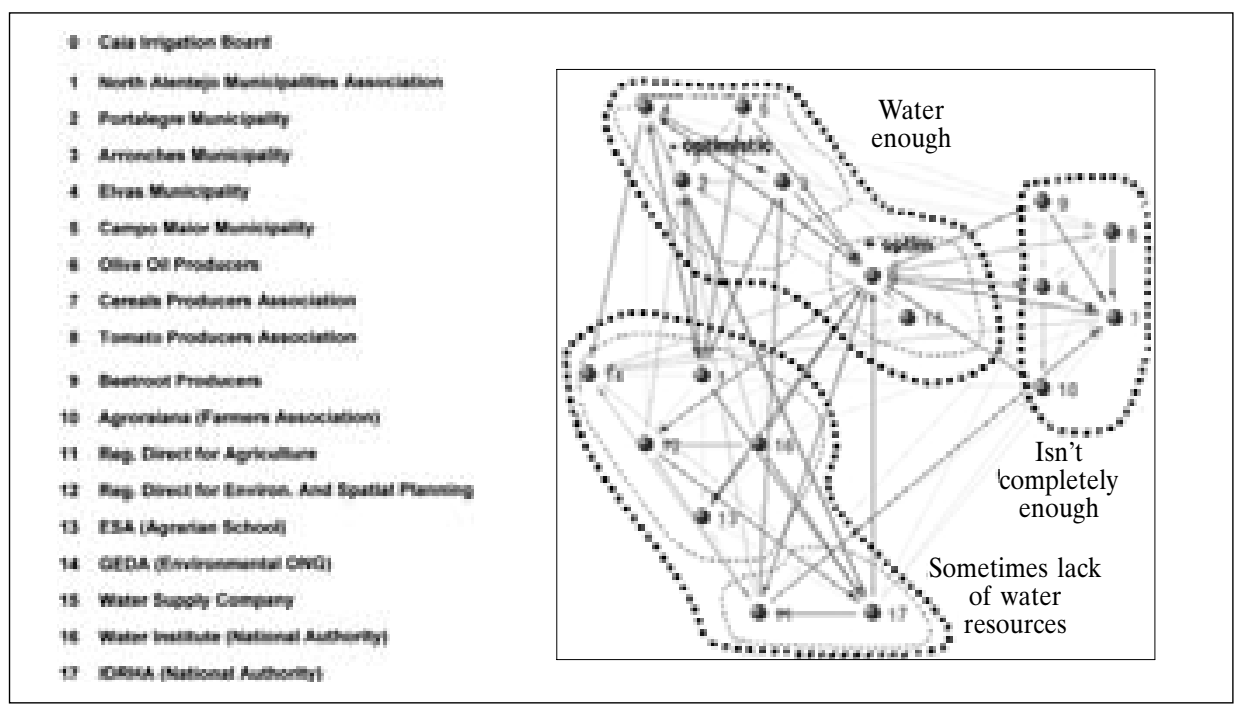

tial issues on the management of water resources in the catchment.

This analysis shows how the different actors become closer or more distant in accordance with specific issues and in this process create cleavages within the decision making process. Therefore, it is possible to see that two main groups can be formed when the subject of Water Demand and Supply is in discussion: one concerns the actors that supply water (for agriculture and other uses) in the catchment; the other relates to the actors that receive and use the water (Figure 6).

Another example of different associations of stakeholders in sub-groups with the social net- work refers to their perceptions about water availability in the catchment. This is a quite controversial issue within the network that produces significant divisions among the stakeholders. On one hand, the more optimistic actors who think that there is enough water for all the uses, are also those responsible for supplying water in the catchment. On the other hand, it is the entities responsible at regional and national level for agriculture in Caia catchment e.g. IDRHA and the Regional Directorate for Agriculture that consider situations of water shortages occur more frequently:

A last example concerns the association of actors according to their contribution for water
Figure 8. Specific objectives of stakeholders according to their contribution for water resources management.

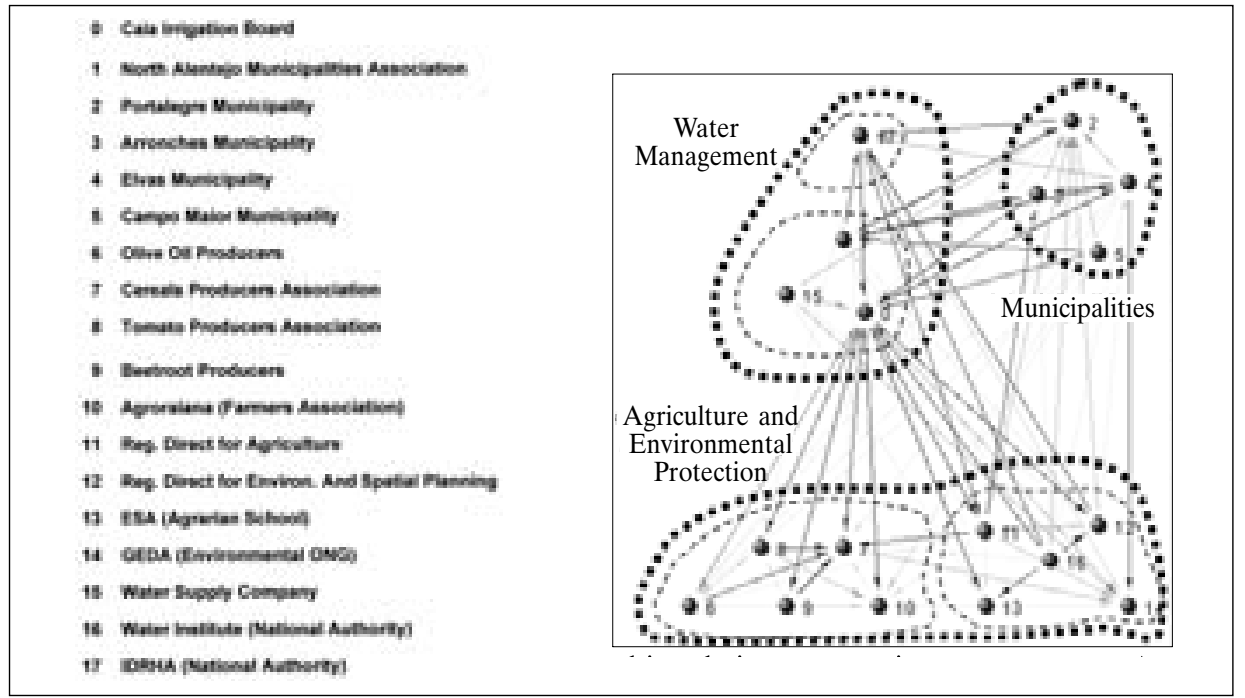


resources management in the Caia catchment. The municipalities are clearly separated from the other actors in the network. The group of actors that have a key involvement in the management of Caia catchment water resources comprises the national authority responsible for rural development and agricultural hydraulics (IDRHA), the Water Supply Company and Caia Irrigation Board, both of them responsible for supplying water at local and regional levels. The agricultural and environmental protection group corresponds to a residual group, in which there is a more consistent sub-group representing the farmers' associations (Figure 8).

\section{Concluding remarks}

Caia's network has some particularities: the overall amount of network structures is low; however, some groups, defined in relation to some issues, are strong. An analysis of macrostructure and microstructure results reveals three structural features of Caia's social network:

- A clear separation into three groups of actors: farmers associations, municipalities and national level entities.

- Within these three groups the density and cohesion are generally greater than in the global network.

- The level of connection between the groups is strong.

One stakeholder (Caia Irrigation Board) has great control over the structure of the local network. The Caia Irrigation Board manages the water from the reservoir and. therefore, controls the supply of water to the framers in the irrigation scheme and has a strong influence in supplying water for other uses. Due to its local setting, it plays a central role in the social interactions of the network making it a key reference to any contact within Caia network, and also the strongest interface between the different clusters and the best way to establish contacts among different levels of decision-making.

However, the Portuguese governance system is characterised by the great importance of the central administration. The level of regional administration is very weak, if not completely nonexistent, and results from the delegation of power from the central administration. Therefore, two external actors (INAG and IDRHA), both national public authorities for the management of water resources, for the conservation and use of water resources in agriculture and for the development and funding of irrigation schemes, have a crucial influence on all the actors playing a role in water management in the Caia catchment.

Social network analysis is an important tool to understand the structure of interactions among a given set of actors. However, it should take into account that social networks are entities in continuous change. Thus, social network analysis is an attempt to make a static picture of an evolving complex social structure which is highly conditioned by changes occurring in the individuals that constitute it. Therefore, the individuals chosen to be interviewed should have an intensive knowledge of the organisation activities they represent. Nevertheless, in larger organisations, it is quite difficult to find people with complete knowledge about all types of its organisation's interactions. One of the conclusions arising from the analysis of local social network is that this type of study must be seen not only as a collection of measures and methods to find out certain parameters about network characteristics, but also as a tool to help improving the communication within the network. This tool must be at the service of the end users and other keystone stakeholders identified.

The study of the Caia catchment social network related with water resource management is a good example of how stakeholders with very different fields and levels of action interact. It demonstrates the importance of analysing the delicate balance established between a wide range of local, national, private and public actors.

\section{Acknowledgements}

The work reported in this paper was developed under the MULINO project: Multi-sectoral, Integrated and Operational decision support system for sustainable use of water resources at the catchment scale (IVK1-CT2000-00082). This interdisciplinary project was developed by research teams from Portugal, Italy, United Kingdom, Belgium and Romania. Concluded in December 2003 and funded by the European Union, DG Research, in the frame of the Programme "Energy, Environment and Sustainable Development". 


\section{References}

Bernard H.R., Killworth P., Sailer L. 1981. Summary of research on informant accuracy in network data and the reverse small world problem. Connections, 4:11-25.

Brown D. 1999. Principles and practice of forest co-management: evidence from West-Central Africa. European Union Tropical Forestry Paper 2. Overseas Development Institute, London.

Cater E., Goodall B. 1992. Must tourism destroy its resource base? In: Mannion A.M., Bowlby S.R. (eds.): Environmental Issues in the 1990s, 309-324. Wiley, Chichester.

Cernea M.M. (ed.) 1985. Putting people first: Sociological variables in rural development. Oxford University Press, New York.

Christensen A., Sullaway M., King C. 1983. Systematic error in behavioral reports of dyadic interaction: Egocentric bias and content effects. Behavioral Assessment, 5:131-142.

Constant D., Kiesler S., Sproull L. 1994. What's mine is ours, or is it? A study of attitudes about information sharing. Information Systems Research, 5:400-421.

Caveau S. 1995. Portugal Geográfico. Edições João Sá da Costa, Lisboa.

Degenne A., Forsé H.B. 1994. Les réseaux sociaux. Ed. Armand Colin, Paris.

EC 2003. EC Common Strategy for the Water Framework Directive (2000/60/EC). Guidance Document No. 8: Public participation in relation to the Water Framework Directive. Active Involvement, Consultation and Public Access Information, Office for the Official Publications of the European Communities, Luxembourg.

Everett M.G., Borgatti S.P. 1999. The centrality of groups and classes. Journal of Mathematical Sociology. 23:181-201.

Faria R.L., Paz B.J. 2002. Aproveitamentos Hidroagrícolas do Grupo II, em Exploração - Actualização de algumas características e elementos estatísticos até ao ano de 2001. IDRHA, Lisboa.

Ferreira A.B., Ferreira D.B., Machado C.R., Machado M.J., Pereira A.R., Ramos C., Rodrigues M.L., Zêzere J.L. 1993. A erosão do solo e a intervenção do Homem no Portugal Mediterrâneo. Linha de Acção de Geografia Física, 31, Centro de Estudos Geográficos, Lisboa.

Freeman L. 1979. Centrality in Social Networks: A Conceptual Clarification. Social Networks, 1:211-213.
Haythornthwaite C. 1996. Social network analysis: An approach and technique for the study of information exchange. Library and Information Science Research, 18:323-342.

Jorge R., Lourenço N., Machado C.R., Rodrigues L. 2002. Sustainable tourism development and local participation: towards good governance. Coastin Newsletter, 7:2-5.

Kochen M. 1989. The small world. Norwood, Ablex.

Lemieux V. 1999. Les réseaux d'acteurs sociaux. PUF, Paris, $146 \mathrm{p}$.

Levine J., Mullins N. 1978. Structuralist analysis of data in sociology. Connections, 7:16-23.

Lourenço N. 2001. Equity, human security and environment: Key elements of sustainable development. Coastin. A Coastal Policy Research Newsletter, 5:2-5.

Lourenço N., Machado C.R., Jorge M.R., Rodrigues L. 2002. Sustainability: Importance of social networks in the decision-making processes. In: Proceedings of the Conference Policies and Tools for Sustainable Water Management in the EU. (Published in CD Available at: http://siti.feem.it/mulino/dissem/intcon/confere.html)

Natividade J.V. 1950. Subericultura. Ministério da Agricultura, Lisboa.

Risse T. 2002. Democratic Global Governance in the 21st Century. Available on-line at: http://www.unc.edu/depts/ europe/conferences $/ \mathrm{mlg} /$ papers/risse1.doc. Last accessed 03-10-2002.

Sachs I. 1995. Searching for new Development Strategies. The Challenges of the Social Summit, Paris, UNESCO/MOST - Policy Papers 1.

SNIRH 2001. Sistema Nacional de Recursos Hídricos. INAG. Database available on-line at: http://snirh.inag.pt/cgi-bin/snirh/snirh.tcl?SCRIPT = covers\&BA$\mathrm{CIA}=4$. Last accessed 03-10-2002

Sproull L., Kiesler S. 1991. Connections: New ways of working in the networked organisation. MIT Press, Boston.

Wasserman S., Faust K. 1994. Social network analysis: Methods and applications. Cambridge University Press, Cambridge.

Wellman B. 1992. Which types of ties and networks provide which types of support? In: Lawler E., Markovsky B., Ridgeway C., Walker H. (eds.): Advances in group processes, 207-235. JAI Press, Greenwich, CT.

White D.R., Harary F. 2001. The Cohesiveness of Blocks in Social Networks: Node Connectivity and Conditional Density. Sociological Methodology, 31:305-359. 